Annals of the University of Craiova

The Chemistry Series

Volume XLVII, No. 2 (2021) 53-59

homepage: chimie.ucv.ro/anale/

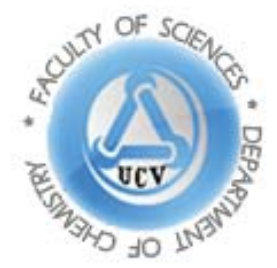

\title{
Degradation of Methyl Blue by Fenton process
}

\section{Research article}

Mădălina Drăgoi ${ }^{*}$, Cătălina Ionescu ${ }^{1}$, Anca Moanță ${ }^{1}$, Cristian Tigae1, Iva Jenic ${ }^{1}$, Simona Daniela Neamțu $u^{2}$

${ }^{1}$ Universitatea din Craiova, Facultatea de Ştiinţe, Departamentul de Chimie, Calea București 107i, Craiova

${ }^{2}$ Universitatea de Medicina si Farmacie, Facultatea de Farmacie, Str. Petru Rareş nr. 2-4 Craiova 200349

*E-mail: madalinadragoi83@yahoo.com

Received: 30.09.2021 / Accepted: 02.11.2021 / Published: 27.12.2021

\begin{abstract}
In this study, the oxidative degradation of Methyl Blue (MB) triphenylmethane dye, in aqueous solution by Fenton oxidation process was investigated. The UV-Vis spectral changes of Methyl Blue dye during discoloration process were studied. Kinetic study was done to find out the effect of $\mathrm{pH}$ on discoloration rate of dye solution.
\end{abstract}

Keywords: triphenylmethane dye, Methyl Blue, Fenton oxidation, kinetic study

\section{INTRODUCTION}

Industrial wastewaters contain a wide variety of organic substances like dyes, pesticides, phenols [1, 2]. These pollutants are posing severe threats to the living organisms due to their harmful and toxic effects. Dyes are highly toxic and pose the strong tendency toward eutrophication [2]. Only $47 \%$ of synthetic dyes are biodegradable.

DOI: 10.52846/AUCCHEM.2021.2.06 
Conventional techniques for wastewater treatment (like precipitation, adsorption and coagulation/flocculation) produce secondary sludge and require a long operation time. Advanced oxidation processes (AOPs) are effective technologies for organic compounds degradation [3]. Among AOPs, Fenton process is very promising because it offers a cost-effective source of hydroxyl radicals, achieves high reaction yields and it is easy to operate $[4,5]$. The Fenton reagent is effective for treating industrial wastewater components such as pesticides [6], aromatic amines [7], surfactants [8] and a wide variety of dyes $[9,10]$.

The main objective of this study was to analyze the influence of $\mathrm{pH}$ on Methyl Blue degradation with Fenton reagent.

\section{MATERIALS AND METHODS}

\subsection{Materials}

The triphenylmethane dye Methyl Blue, ferrous sulfate $\left(\mathrm{FeSO}_{4} \bullet 7 \mathrm{H}_{2} \mathrm{O}\right)$, hydrogen peroxide $(30 \% \mathrm{w} / \mathrm{w})$ and sulfuric acid were all purchased from Fluka or Aldrich. All reagents were used without further purification. Distilled water was used to prepare the colored solutions. The molecular structure of Methyl Blue is presented in Figure 1.

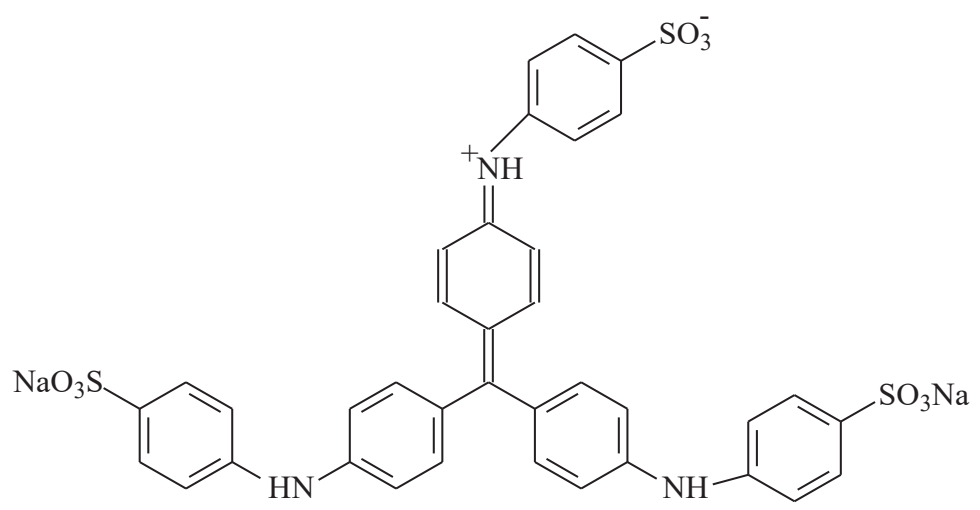

Figure 1. Chemical structure of Methyl Blue 


\subsection{Analysis methods}

Batch experiments of Fenton oxidation process were performed in an Erlenmeyer glass equipped with refrigerator bottom with Fenton concentration of $4 \times 10^{-5}$ mol L-1 of $\mathrm{Fe}^{2+}$ and $2 \times 10^{-3} \mathrm{~mol} \mathrm{~L}^{-1}$ of $\mathrm{H}_{2} \mathrm{O}_{2}$. All experimental determinations were performed for aqueous solutions of dye, with an initial concentration of $6.5 \times 10^{-5} \mathrm{~mol} \mathrm{~L}^{-1}$ at temperature of 25 ${ }^{\circ} \mathrm{C}$ and different $\mathrm{pH}$ values: 3, 4, 5 and 6, respectively.

For each experiment, $100 \mathrm{~mL}$ of dye solution were introduced into the Erlenmeyer flask. Predetermined quantities of ferrous sulphate and hydrogen peroxide were added to the Erlenmeyer flask. pH was adjusted to the above mentioned values by using $0.05 \mathrm{M} \mathrm{H}_{2} \mathrm{SO}_{4}$ and was measured with a model Consort C533 pH-meter. The Erlenmeyer flask containing dye solution was placed in a thermostat water bath with constant temperature. The solution was stirred by a magnetic stirrer.

The kinetics of dye oxidation was followed by taking samples at 1-minut intervals. The UV-Vis spectra of Methyl Blue samples were recorded from 200-800 $\mathrm{nm}$ by using an UV-Vis Varian Cary 50 Bio spectrophotometer at the maximum absorption wavelength. In visible range, the maximum absorption wavelength $\left(\lambda_{\max }\right) \mathrm{MB}$ is $600 \mathrm{~nm}$. This peak corresponded to the absorption of the $n-\pi^{*}$ transition related to the quinone structure and was used in order to monitor the compound discoloration. In the UV region, a shoulder around $213 \mathrm{~nm}$ and a band at $312 \mathrm{~nm}$ were observed. These wavelengths were ascribed to $\pi-\pi^{*}$ transitions corresponding to the conjugated aromatic system (Figure 2). Therefore, concentration of dye in water was measured at $\lambda_{\max }$.

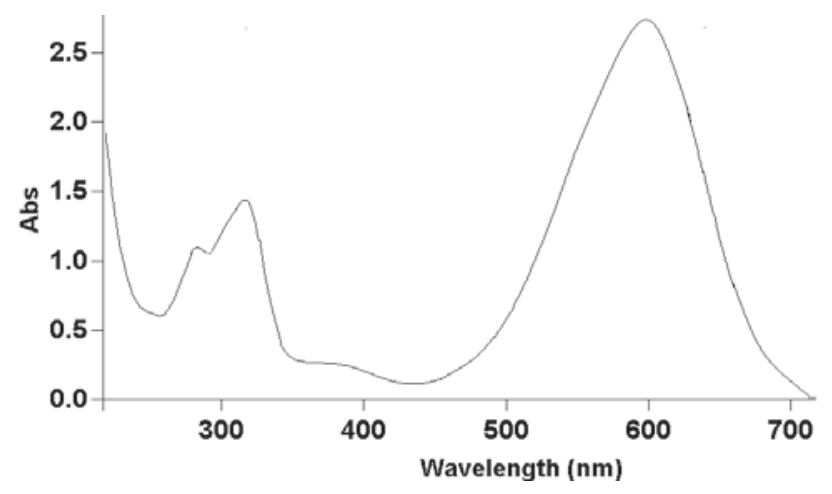

Figure 2. UV-Vis absorbance spectrum of Methyl Blue 


\section{RESULTS AND DISCUSSION}

\subsection{Chemical degradation}

Experimental determinations were performed for aqueous solutions of $\mathrm{MB}$ at $25{ }^{\circ} \mathrm{C}$ and different $\mathrm{pH}$ values: 3, 4, 5 and 6, respectively.

The color removal was determined using Eq. 1.

Color removal $(\%)=\left(1-\mathrm{A} / \mathrm{A}_{0}\right) \cdot 100$

where $A_{0}$ and $A$ are the absorbances at initial time and after time $t$, respectively.

$\mathrm{UV}-\mathrm{V}$ is spectrum obtained during the degradation of $\mathrm{MB}$ at $\mathrm{t}=25^{\circ} \mathrm{C}$ and $\mathrm{pH}=4$ is presented in Figure 3. It can be observed that the absorbance decreases in time which demonstrates the discoloration and degradation of Methyl Blue. For the other $\mathrm{pH}$ values, similar spectra were obtained.

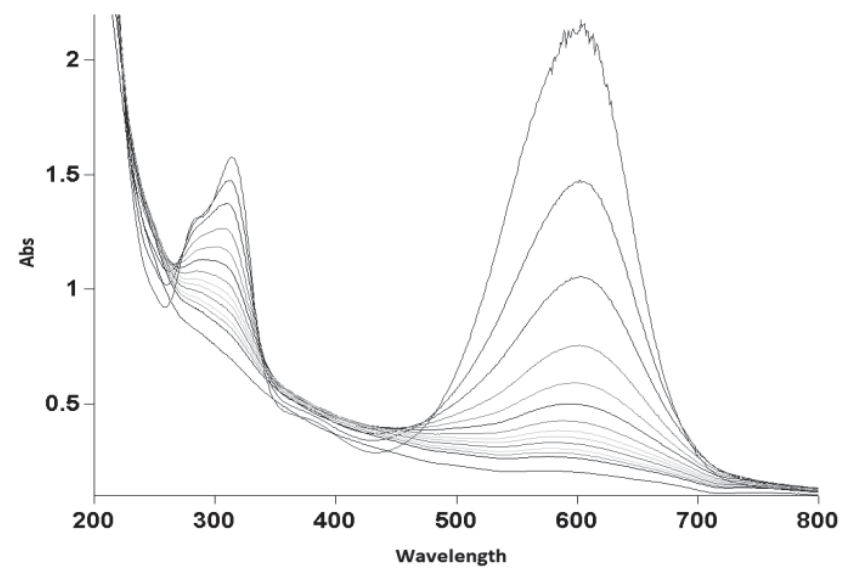

Figure 3. UV-Vis spectral changes during the degradation of Methyl Blue in the presence of Fenton reagent at $\mathrm{t}=25^{\circ} \mathrm{C}$ and $\mathrm{pH}=4$

Figure 4 illustrates the effect of $\mathrm{pH}$ on the Fenton oxidation of Methyl Blue triphenylmethane dye. With increasing $\mathrm{pH}$, the color removal values at the same reaction time present a significant decrease hence a smaller rate of discoloration. Thus, the color removal after $1 \mathrm{~min}$ decreases from $46.68 \%$ calculated at $\mathrm{pH}=3$ to the value of $32.67 \%$ at $\mathrm{pH}=6$. 


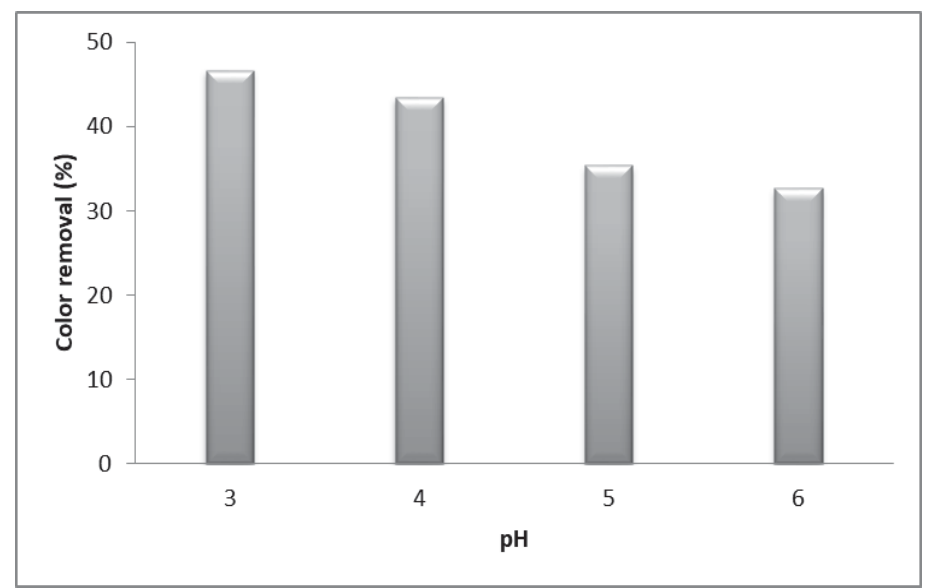

Figure 4. Effect of $\mathrm{pH}$ on Methyl Blue Fenton oxidation

\subsection{Kinetic approach}

The kinetics of Methyl Blue degradation by Fenton oxidation process under various temperature values has been investigated. For discoloration of triphenylmethane dyes by Fenton reagent, first order kinetic model has been suggested. The expression of concentration variation in time for first order reaction kinetics is the following:

$$
\ln \frac{[\text { dye }] \mathrm{o}}{[\text { dye }]}=\mathrm{k} \mathrm{t}
$$

where [dye] is the initial concentration of dye $(\mathrm{mol} / \mathrm{L})$; [dye] is the dye concentration at a certain moment " $\mathrm{t}$ " $(\mathrm{mol} / \mathrm{L})$; $\mathrm{k}$ represents the rate constant $\left(\mathrm{min}^{-1}\right)$.

Because the absorbance is directly proportional with the concentration of dye subjected to degradation, Eq. 2 can be written as follows:

$$
\ln \frac{A \mathrm{o}}{A}=\mathrm{kt}
$$

where:

A 0 and $\mathrm{A}-$ absorbances of the dye at initial time and at time " $\mathrm{t}$ ", respectively; 


\section{Verification of integrated rate law}

The curves $\ln \left(A_{0} / A\right)=f(t)$ obtained from experimental data during the Fenton oxidation of $\mathrm{MB}$ are shown in Figure 5.

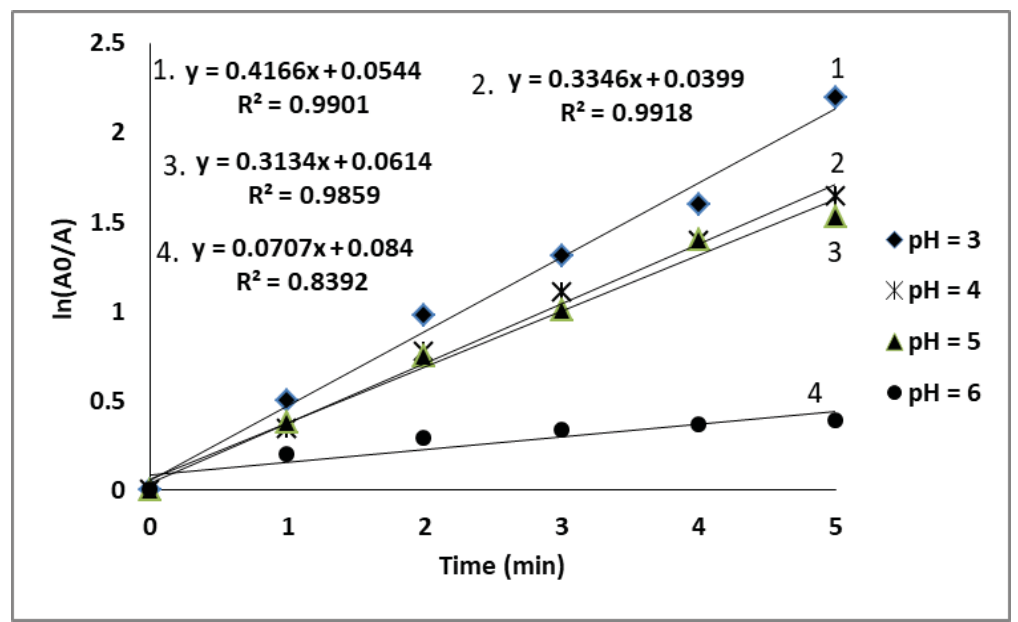

Figure 5. Plot of $\ln \left(\mathrm{A}_{0} / \mathrm{A}\right)=\mathrm{f}(\mathrm{t})$ in case of $\mathrm{MB}$ degradation at different $\mathrm{pH}$ values

The equations and deviations from linearity $\left(\mathrm{R}^{2}\right)$ are inserted in the graph. Rate constant $(\mathrm{k})$ decreases with the increasing of $\mathrm{pH}$ and have values ranging from $0.3134 \mathrm{~min}^{-1}$ for $\mathrm{pH}=5$ to $0.4166 \mathrm{~min}^{-1}$ for $\mathrm{pH}$ $=3$. The $\mathrm{R}^{2}$ values are close to unity at $\mathrm{pH}=3-5$ which indicates the pseudo-first-order kinetic model is applicable to the MB degradation.

\section{CONCLUSION}

The present study demonstrated that triphenylmethane dye Methyl Blue can be degraded effectively by Fenton process.

The increase of $\mathrm{pH}$ from 3 to 6 leads to a decrease of color removal from $46.68 \%$ to $32.67 \%$, after $1 \mathrm{~min}$ of reaction.

The Fenton oxidation process of Methyl Blue in aqueous medium at $\mathrm{pH}=3-5$ follows the first order reaction kinetics. 


\section{REFERENCES}

1. M. Saeed, M. Usman and A. Haq, Photochemistry and Photophysics - Fundamentals to Applications, London, 2018.

2. U. Shanker, M. Rani and V. Jassal, Environ. Chem. Lett., 15 (2017) 623.

3. H. Anwer, A. Mahmood, J. Lee, K.-H. Kim, J.-W. Park and A. C. K. Yip, Nano Res., 12 (2019) 955.

4. A. S. Yargic and N. Ozbay, Int. J. Adv. Res. Chem. Sci., 3 (2016) 38.

5. S. Papic, D. Vujevic, N. Koprivanac and D. Sinko, J. Hazard. Mater., 164 (2009) 1137.

6. K. Barbusinski and K. Filipek, Pol. J. Eviron. Stud., 10 (2001) 207.

7. I. Casero, D. Sicilia, S. Rubio and D. Perez-Bendito, Water. Res,. 31 (1997) 1985.

8. S. H. Lin, C. M. Lin and H. G. Leu, Water. Res., 33 (1999) 1735.

9. M. Drăgoi, A. Moanţă, C. Tigae and Marius Dragoi, Rev. Chim. (Bucharest), 66 (2015) 1273.

10. M. Drăgoi, A. Samide and A. Moanță, Rev. Chim. (Bucharest), 62 (2011) 1195. 